\title{
Expression of a collagen gene in mesenchyme lineages of the Strongylocentrotus purpuratus embryo
}

\author{
Lynne M. Angerer, ${ }^{2}$ Scott A. Chambers, ${ }^{1}$ Qing Yang, ${ }^{2}$ Malabi Venkatesan, ${ }^{1,3}$ Robert C. Angerer, ${ }^{2}$ and \\ Robert T. Simpson 1 \\ ${ }^{1}$ Laboratory of Cellular and Developmental Biology, NIDDK, National Institutes of Health, Bethesda, Maryland 20892 USA; \\ ${ }^{2}$ Department of Biology, University of Rochester, Rochester, New York 14627 USA
}

\begin{abstract}
We have previously described cloning of an exon of a sea urchin collagen gene and shown that its expression is temporally regulated during embryogenesis, beginning during blastula formation. We have now localized the protein encoded by the gene and the sites of its mRNA synthesis in the developing embryo. Antibody to a synthetic peptide reacts with a $208,000 M_{r}$ protein that is digestible by collagenase. Fractionation of pluteus stage embryos demonstrates that the protein is localized primarily with cells that form the syncytium of primary mesenchyme that elaborates the larval endoskeleton; furthermore, immunofluorescence localizes the epitope to the periphery of the endoskeletion in situ. Transcripts of the gene accumulate only in mesenchyme cells, especially those of the primary mesenchyme lineage. Measurements of absolute transcript abundance show that collagen mRNA is present in blastula primary mesenchyme cells at 600-700 copies per cell and at about fourfold lower amounts in other mesenchyme cells.
\end{abstract}

[Key Words: Sea urchin; hybridization; anti-collagen]

Received August 31, 1987; revised version accepted December 2, 1987.

During sea urchin embryogenesis, the mesenchymal lineages are derived from the vegetal regions of egg cytoplasm. At the fourth cleavage division, the vegetal tetrad of cells divide unequally and obliquely, forming macromeres and micromeres. Another unequal division of the micromeres produces four smaller and four larger cells; the latter divide to give rise to about 32 primary mesenchyme cells. Presumptive primary mesenchyme cells penetrate the basal lamina to enter the blastocoele cavity shortly after hatching (18-20 hr postfertilization at $15^{\circ} \mathrm{C}$ for Strongylocentrotus purpuratus| and migrate to form a ring around the base of the archenteron in the vegetal half of the interior of the gastrula. Later, these cells rearrange into two ventrolateral aggregates that eventually adopt a triradiate shape, form a syncytium, and within that deposit calcium carbonate to form the spicular endoskeleton of the mature pluteus larva. The smaller progeny of the four micromeres divide only once more during the first 3 days of the development; these eight cells reside just below the tip of the invaginating archenteron during gastrulation (Pehrson and Cohen 1986). Subsequently, they contribute to the coelomic rudiments, outpocketings from the esophageal-mouth region of the pluteus larva. Secondary mesenchyme cells arise at the tip of the archenteron where they extend

${ }^{3}$ Current address: Department of Bacterial Immunology, Walter Reed Army Institute for Medical Research, Washington, DC 20307 USA. contractile filopodia that attach to the blastocoele wall at the animal pole of the embryo. After fusion of the archenteron with the ectodermal wall, some of the secondary mesenchyme cells migrate into the blastocoele and give rise to various other cell types, including pigment cells.

Recently, using a murine collagen cDNA clone as a probe, we described isolation of a genomic clone of $S$. purpuratus DNA whose sequence indicated that it encoded part of a collagen molecule (Venkatesan et al. 1986). This conclusion was based on the following criteria: (1) a 212-bp segment of the clone, a putative exon, coded a protein sequence consisting of $[\mathrm{GLY}-\mathrm{X}-\mathrm{Y}]_{n}$ with only one interruption, which can be interpreted as loss of a glycyl residue; (2) the inferred protein sequence is rich in proline; (3) splicing sequences flank the presumptive exon; and (4) the cloned sequence hybridized to a large, approximately $9-\mathrm{kb}, \mathrm{mRNA}$. The mRNA transcribed from this gene is temporally regulated during sea urchin development, rapidly accumulating at blastula stage (Venkatesan et al. 1986). We now report the spatial distribution of the protein and RNA products of this collagen gene during development and show that both are confined to mesenchymal tissues.

\section{Results}

To localize the protein product of the collagen gene, an 
undecapeptide corresponding to the region of the coding sequence around the discontinuity in the GLY-X-Y motif, Gly-Asn-Ser-Ile-Pro-Gly-Ser-Pro-Gly-Glu-Lys, was synthesized, coupled to bovine serum albumin, and used to immunize two rabbits. Both animals developed antibody to the peptide. When total proteins of pluteus stage larvae were separated by electrophoresis on SDS polyacrylamide gels and transferred to nitrocellulose membranes, these antibodies identified a protein of $M_{r}$ 208,000 and a smeared region of higher molecular weight protein (Fig. 1A). Other peptides that reacted with the antisera were also detected with preimmune serum (data not shown), suggesting that the $208,000 M_{r}$ peptide was one that contained the epitope encoded by the putative collagen gene sequence. This conclusion was supported by the disappearance of this peptide when proteins were treated with collagenase prior to electrophoresis (Fig. 1A). The smeared material also was collagenase digestible, suggesting that it is made up of aggregates of collagen. As expected, peptides that reacted with preimmune serum were not altered by treatment with the specific protease.

Using minor modifications of the embryo fractionation method of McClay (1986), we dissociated pluteus larvae into fractions enriched in certain cell types: ectoderm, secondary mesenchyme, endoderm, spicules + primary mesenchyme + basal lamina + some residual endoderm, and clean spicules. Equal amounts of protein from each of these fractions were separated electrophoretically, blotted, and probed with the rabbit antiserum to the collagen peptide (Fig. 1B). The $208,000 M_{r}$ immunoreactive peptide was present in total pluteus proteins (lane 1) and in that fraction containing primary mesenchyme/spicule/basal lamina/residual endoderm proteins (lane 5). It was not present in the other tissue fractions (lanes 2-4), although it may be present in low amount in SDS-washed spicules (lane 6). The absence of the peptide from endoderm suggests that it is associated with primary mesenchyme and/or basal lamina in the tissue fraction shown in lane 5 of Figure 1B. The smeared region and the peptide of $M_{r}>208,000$ in lane 6 of Figure 1B were also detected with preimmune serum.

To further localize the protein, we utilized the antisera in indirect immunofluorescence of $S$. purpuratus whole embryos. Figure 2 presents paired brightfield $(A, C)$ and fluorescence $(B, D)$ photomicrographs for embryos stained with preimmune $(A, B)$ and immune $(C, D)$ serum. At the dilution utilized, there is a generalized background fluorescence seen with all sera. However, immune sera also stain the outer boundary of the spicules, which does not occur for preimmune sera (cf. Fig $2 \mathrm{~B}$ and $\mathrm{D}$ ). Because of the very narrow focal plane at this
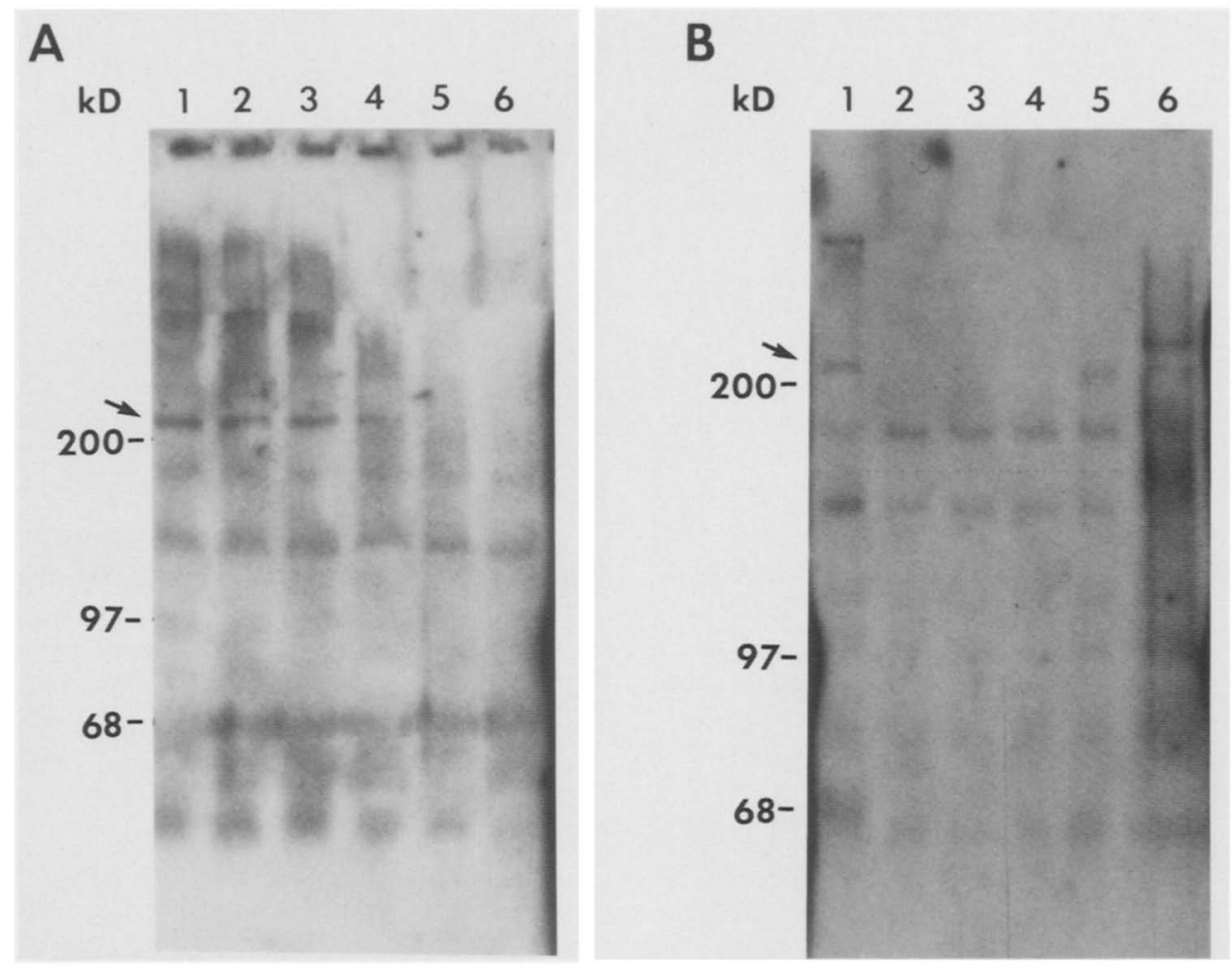

Figure 1. Western blots to identify the sea urchin collagen protein and its location. Blots were stained with anti-collagen peptide antibody as described in Methods. (A) Gel electrophoresis of total sodium-dodecyl-sulfate (SDS)-soluble protein from $S$. purpuratus pluteus stage embryos. The sample in lane 1 was held at $0^{\circ} \mathrm{C}$. Samples in lanes $2-6$ were treated with $0,0.003,0.03,0.3$, and 3 units of collagenase (Sigma) in buffer (suppliers recommended buffer supplemented with proteinase inhibitors) for $30 \mathrm{~min}$ at $37^{\circ} \mathrm{C}$. The arrow notes the position of migration of the $208,000 M_{r}$ peptide. $(B)$ Gel electrophoresis of total SDS-soluble proteins from tissue fractions of S. purpuratus pluteus stage embryos. Tissues analyzed are total embryo (lane 1), ectoderm (lane 2), secondary mesenchyme (lane 3), endoderm (lane 4), spicules + basal lamina + primary mesenchyme + residual endoderm (lane 5), and SDS-washed spicules (lane 6). 
magnification, as well as the relatively weak staining of the antibody, only short segments of the spicule can be viewed at one time. Alternative focal planes throughout the embryo display similar fluorescence. The relatively weak staining of these structures could be a result of the steric exclusion of the antigenic site by the highly ordered triple helical structure of the collagens. Detectable enhanced fluorescence is not seen associated with the basal lamina lining the blastocoele.

We feel it is likely that the collagen epitope that is stained in the pluteus whole mounts is a component of the sheath of the spicule and not within the spicule itself. This conclusion, based primarily on the observation of staining of the peripheral regions of the spicule, is
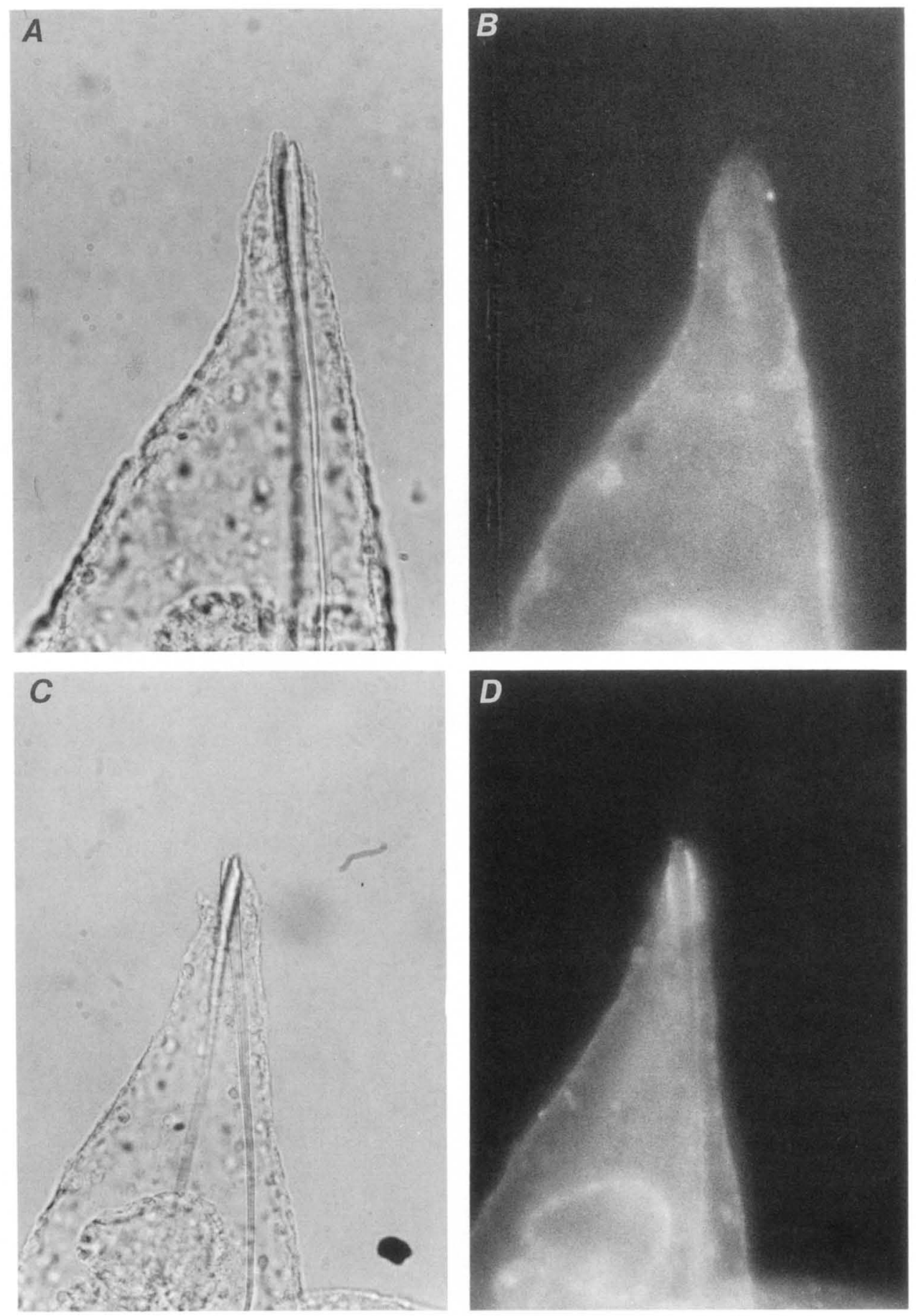

Figure 2. Location of the collagen epitope in pluteus larvae by immunofluorescence. Brightfield micrographs $(A, C)$ and indirect immunofluorescence micrographs $(B, D)$ of whole-mount $S$. purpuratus embryos reacted with preimmune $(A, B)$ or immune $(C, D)$ serum and then stained with a fluorescein-conjugated goat anti-rabbit IgG. 
supported by two other observations. First, embryos with portions of the spicule protruding from the body of the organism loccasionally found in healthy, late stage cultures that have been vigorously agitated or aerated) do not have staining over the exposed portion of the spicule, suggesting that a surrounding sheath was stripped from the extruded endoskeleton. Second, as shown in Figure 1B, spicules washed in SDS had little reactivity to the antibody on Western blots. If the collagen epitope was a spicular component, one would expect a greater reaction with detergent-washed spicules (Fig. 1B, lane 6) than with the spicule + primary mesenchyme sample (lane 5); in fact, the opposite situation obtains. Because of the relatively high background for the immunofluorescence experiments, we cannot confidently preclude the presence of minor amounts of the antigen at sites other than the spicule sheath. Specific staining was abolished by incubation of the antiserum with bovine serum albumin (BSA) coupled to peptide; incubation with BSA alone did not alter the staining pattern.

Because collagen is an extracellular protein, we used in situ hybridization to identify the cells expressing this gene. We prepared a subclone in a riboprobe expression vector that contained the exon of the genomic clone flanked by only 5 bp to the $5^{\prime}$ side and 20 bp to the $3^{\prime}$ side of the exon. Sense and antisense transcripts of this clone were then used for in situ hybridization with sections of urchin larvae at various developmental stages.

mRNA complementary to this probe was not detectable in maternal RNA (see Fig. 3E and Venkatesan et al. 1986) but was expressed specifically in mesenchymal cell lineages of sea urchin embryos in stages from hatching blastula to pluteus, as illustrated in Figure 3. Panels A-D show phase-contrast photographs of 16-cell, 19-hr hatched blastula, 23-hr mesenchyme blastula, and 42-hr gastrula stages to illustrate morphology. The same sections were also photographed with dark-field illumination $(E-H)$ to illustrate labeling patterns. Panels $M$, $\mathrm{N}$, and $\mathrm{O}, \mathrm{P}$ are similar pairs of sections of 68 -hr plutei. Control hybridizations with sense probe RNA to sections corresponding to the same stages shown in $\mathrm{A}-\mathrm{H}$ are shown in panels $\mathrm{I}-\mathrm{L}$. No signal above background was detectable in any blastomere type of 16-cell embryos, including the micromeres (A,E; arrows), which are the progenitors of primary mesenchyme /compare $\mathrm{E}$ and I). Similarly, no signal was evident in 12-hr embryos (data not shown), but grain densities began to increase in a small region of the blastula wall just after hatching when primary mesenchyme cells were just beginning ingression (F). By mesenchyme blastula stage, the level of collagen mRNA in primary mesenchyme cells within the blastocoele had increased substantially $(C, G)$. In addition, some other cells in the vegetal wall were labeled at about a fourfold lower grain density larea between lines in G). This region contains: (1) 8 cells of the small micromere lineage; (2) presumptive secondary mesenchyme; and (3) possibly some residual primary mesenchyme cells that have not yet ingressed. After gastrulation began, different mesenchymal cell types were more clearly identifiable by their positions in the embryo. The same sets of cells that express collagen mRNA in the blastula were also labeled at gastrula stage $(\mathrm{D}, \mathrm{H})$ at approximately the same relative intensities. Clearly, the most heavily labeled cells were those of the primary mesenchyme, located within the blastocoele mostly in the vegetal half of the embryo (arrows). Other cells labeled at lower grain densities are located close to the tip of the archenteron (small micromere descendents and/or secondary mesenchyme) and also within the blastocoele in the animal hemisphere (secondary mesenchyme; arrowheads). In the pluteus $(M, N)$, the most heavily labeled cells were arrayed in the pattern characteristic of primary mesenchyme along the spicules (the spicules are lost in tissue processing). Clusters of heavily labeled cells were found in the anal arms and vertex of the embryo at the ends of the spicules. A second class of less heavily labeled cells was also detected around the gut. In characteristic sections that pass through the esophagus and the adjacent coelomic sacs (O,P; arrows), it can be seen that many cells in the latter tissue, but none in the former tissue, were labeled. Based on examination of a large number of sections and the number of labeled cells in this region, it appears that more cells contain collagen mRNA than can be accounted for solely by the progeny of the small micromeres, implying that some secondary mesenchyme cells may also populate the coelomic sacs at this stage.

We believe that these in situ hybridizations reflect the distribution of a single mRNA species corresponding to the probe sequence. Previous electrophoretic analyses of whole-embryo RNA populations by hybridization showed only one mRNA complementary to this probe throughout development (Venkatesan et al. 1986). To test this further, we compared the thermal stability of hybrids formed between antisense and sense transcripts of the probe sequence with that of hybrids formed in solution at relaxed stringency $\left(T_{m},-32^{\circ} \mathrm{C}\right)$ between antisense RNA and total RNA from sea urchin gastrulae. The melting profiles of both types of hybrid were congruent, and the $T_{m}$ was consistent with the $57 \% \mathrm{G}+\mathrm{C}$ content of this sequence $182^{\circ} \mathrm{C}$ in $50 \%$ formamide, $0.3 \mathrm{M}$ $\mathrm{Na}^{+}$; data not shown). This rules out the possibility that a significant fraction of probe hybridized to divergent RNA in situ because these hybridizations were carried out under much more stringent conditions $\left(T_{m \prime}-17^{\circ} \mathrm{C}\right)$.

To determine the collagen transcript abundance in RNA of whole embryos, we carried out solution titrations by measuring the mass of antisense probe hybridized to increasing amounts of total sea urchin RNA, as described previously (Lynn et al. 1983). These values, listed in Table 1, show that mRNA complementary to this probe was moderately abundant and was in highest concentration at late gastrula stage. Copies per embryo ranged from about 30,000 at mesenchyme blastula to 70,000 at late gastrula stage. We have recently confirmed this developmental pattern of accumulation with another preparation of RNA.

We estimated the amount of collagen mRNA in primary mesenchyme cells at blastula stage from the number of these cells per embryo, the total number of 


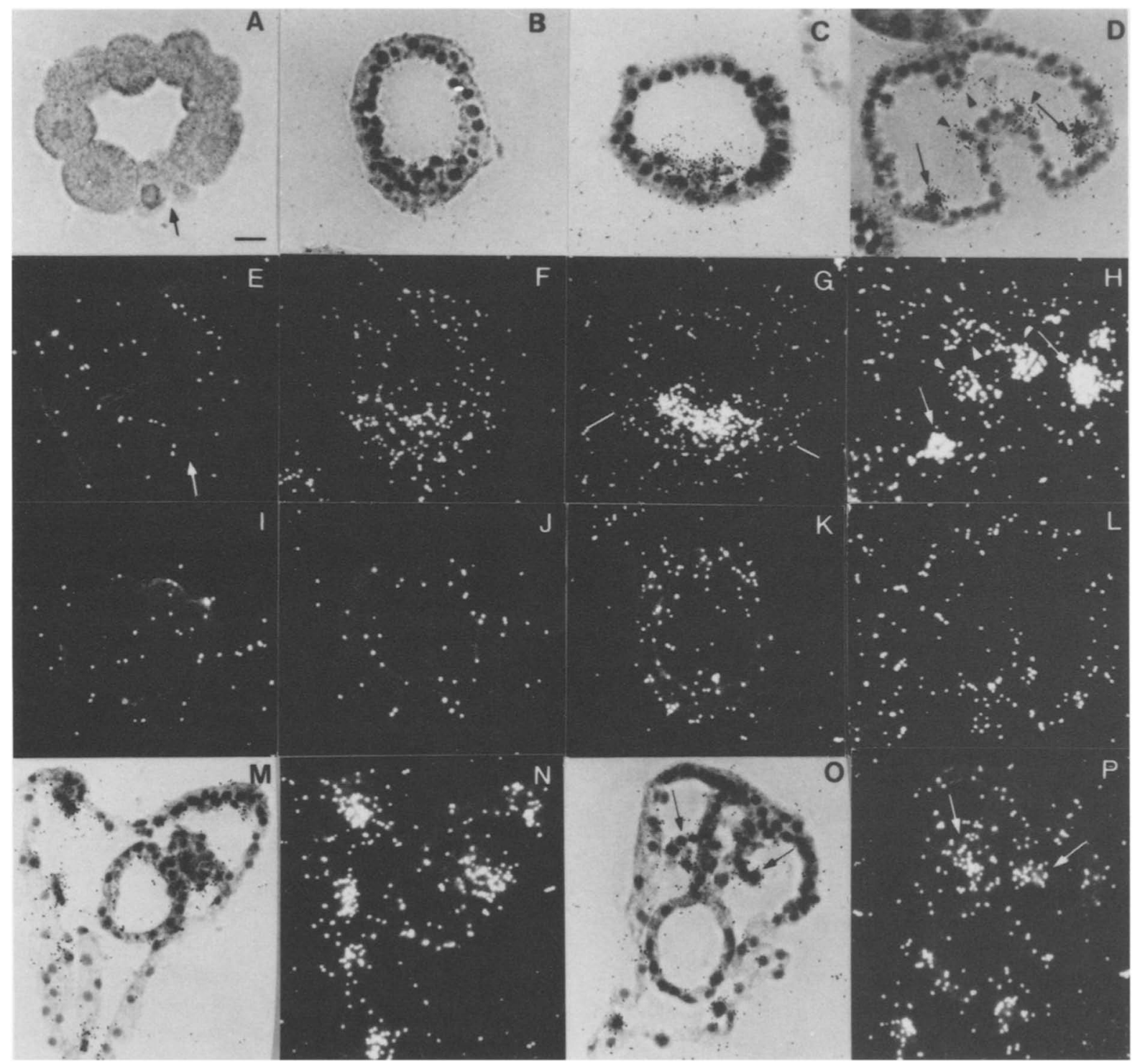

Figure 3. Location of sites of expression of the collagen gene. Sections of sea urchin embryos were hybridized to sense (panels $I-L$ ) or antisense (panels $A-H$ and $M-P$ ) riboprobes synthesized from the collagen exon clone. Panels $A-D$ and $M$ and $O$ are phase-contrast micrographs of embryos at 16-cell; 19 -hr hatched blastula; 23-hr mesenchyme blastula; 42 -hr gastrula; and two samples of 68 -hr plutei, respectively. Panels $E-H$ and $N$ and $P$ are dark-field photomicrographs of the same sections shown in the phase micrographs to emphasize the localization of radioactive labeling. Adjacent sections to those shown in panels $A-H$, but hybridized to the sense probe, are shown with dark-field illumination in panels $I-L$ to illustrate the level of background hybridization. In $A$ and $E$ arrows point to the micromeres. In $\mathrm{G}$, cells labeled at lower intensity at the vegetal pole are found between the lines. In $D$ and $H$, primary and secondary mesenchyme cells are indicated by arrows and arrowheads, respectively. In the pluteus section $|O, P|$, arrows point to the coelomic sacs. The bar in $A$ represents $10 \mu \mathrm{m}$.

labeled cells, their relative grain densities, and transcript number per embryo. Using values of 32 primary mesenchyme cells and about 40 other cells, labeled at grain densities over backgrounds of 13.6 and 3.6 grains $/ 100$ $\mu \mathrm{m}^{2}$ respectively, and 28,000 copies per embryo, we estimate that each primary mesenchyme cell contains 600-700 copies, while other mesenchyme cells have an average of about 180 transcripts.

\section{Discussion}

These data document the spatially regulated expression of a gene encoding a collagen-like protein that, within the limits of detection of these assays, is confined to mesenchyme lineages from hatched blastula through pluteus stages. Other work provides evidence that sea urchin embryos synthesize proteins resembling collagen during these same stages of development. Hydroxyproline is incorporated into proteins preferentially associated with spicules (Pucci-Minafra et al. 1972), and fibrils whose ultrastructure is characteristic of collagen have been detected in the blastocoele /Crise-Benson and Benson 1979/. Proteins have been identified that react with antibodies against vertebrate collagens (Wessel et 
Table 1. Absolute concentrations of collagen mRNA in sea urchin embryos

\begin{tabular}{clc}
\hline $\begin{array}{l}\text { Hours post } \\
\text { fertilization }\end{array}$ & Stage & Molecules/embryo \\
\hline 0 & egg & not detectable \\
23 & mesenchyme blastula & 28,000 \\
29 & late mes. blastula- & 36,000 \\
& early gastrula & \\
41 & gastrula & 48,000 \\
48 & late gastrula & 70,000 \\
68 & pluteus & 62,000 \\
\hline
\end{tabular}

al. 1984) and are present in high concentration in the blastocoele around primary mesenchyme cells and in the basal lamina lining the blastocoele (Wessel and McClay 1987). The involvement of primary mesenchyme cells in synthesis of collagen-like proteins is also suggested by studies showing that cultures enriched in this cell type also contain hydroxyproline-containing proteins whose synthesis is sensitive to inhibitors known to interfere with collagen processing and maturation (Mintz et al. 1981). Recent studies strengthen this conclusion since descendants of pure micromeres, treated with specific inhibitors of collagen metabolism, were able to form spicules only if supplied with a collagen substratum (Blankenship and Benson 1984). Since these cells produce spicules in the absence of inhibitor, it seems likely that they make the collagen required for spiculogenesis. The mesenchyme expression of this gene, as well as the immunofluorescent localization of the protein to the periphery of the spicule, strongly suggest that it encodes the collagen-like protein necessary for spicule formation.

Most of the classification of collagen types derives from the extensive characterization of vertebrate proteins (recently reviewed by Martin et al. 1985). However, the sea urchin gene we have described presents a combination of structural features and tissue specificity that is not readily matched to a vertebrate counterpart. This gene was originally selected by hybridization with a murine type IV, nonfibrillar collagen cDNA probe, and the discontinuity in the GLY-X-Y repeated sequence of the sea urchin gene is also characteristic of vertebrate nonfibrillar collagens. However, vertebrate type IV collagen is associated with basal lamina. Vertebrate fibrillar collagens (type I, II, and III) are those found in interstitial extracellular matrices, and are synthesized by mesenchymal cells. Morphological studies have identified fibrillar molecules in the sea urchin blastocoele, and these fibrils stain with antibodies against vertebrate type I collagen. Wessel and McClay (1987) have shown that in the sea urchin $L$. variegatus, vertebrate type I antibodies react with a protein of $M_{r} 210,000$, while anti-type IV antibodies recognize proteins of $M_{r} 140,000$ and 160,000. Thus, the size of the protein and its mesenchyme origin are more characteristic of vertebrate type I than type IV collagen. While the genomic organization of the sea urchin collagen gene is similar to that of vertebrate genes, with multiple introns (Venkatesan et al. 1986), this does not necessarily imply similar structure-function relationships for the collagen proteins. The variety and function of collagens in sea urchins remain matters for conjecture now and investigation in the future.

The presence of the message in secondary mesenchyme and coelomic rudiments suggests that this collagen could have additional roles in later development. Some cells in the coelomic sacs contain muscle-specific tropomyosin (Ishimoda-Takagi et al. 1984) and high concentrations of muscle actin mRNA (Cox et al. 1986). We can speculate that these proteins may play an interactive role in later differentiation.

The differentiation of the micromere-primary mesenchyme lineage is becoming increasingly well characterized at the molecular level (for review, see Angerer and Davidson 1984). Although micromeres are known to be determined at the 16-cell stage (Okazaki 1975), lineagespecific gene expression has not been detected until near the time of mesenchyme ingression. At that time, there is a burst of biochemical differentiation that includes the synthesis of new proteins (Harkey and Whiteley 1983; Pittman and Ernst 1984), changes in cell adhesivity (Fink and McClay 1985), and appearance of specific cell-surface antigens (Wessel and McClay 1985). In addition to activation of the collagen gene described here, mRNA of CyIIa, a cytoplasmic actin gene, accumulates in presumptive mesenchyme. In contrast to the collagen gene, CyIIa expression is greatly reduced in primary mesenchyme cells shortly after these cells ingress (Cox et al. 1986). While this work was in preparation for publication, characterization of a gene for a major spicule protein was reported; expression of this gene is specific to the primary mesenchyme lineage (Benson et al. 1987; Sucov et al. 1987).

Of particular interest to us is the identification of genes whose regulated expression occurs predominantly in cells of a single lineage that can be isolated to a high degree of purity at several developmental stages (Hynes and Gross 1970; Harkey and Whiteley 1980). Because such cells can differentiate in culture (Okazaki 1975; Harkey and Whiteley 1980; Mintz et al. 1981), they provide a highly suitable system for understanding the regulation of transcription of the collagen gene, one that is critically involved in early morphogenesis (Blankenship and Benson 1984).

\section{Methods}

S. purpuratus were obtained from Pacific Biomarine or Marinus Corp. Gametes were collected, embryos cultured, and RNA isolated as previously described (Wu and Simpson 1985; Venkatesan et al. 1986). Tissue fractionation of pluteus-stage embryos was done using minor modifications of the methods described by McClay (1986). The tissue fraction designated secondary mesenchyme is operationally defined as those cells dissociating after the pigmented ectoderm and prior to dissociation of the tightly adherent endodermal tube. Spicules were washed in $0.1 \%$ SDS at room temperature for $5 \mathrm{~min}$.

An undecapeptide corresponding to a sequence encoded by the collagen exon (Venkatesan et al. 1986) was synthesized, coupled to bovine serum albumin, and to immunize rabbits. The resultant antisera were used for analysis of separated pro- 
tein samples by Western blotting. Proteins soluble after boiling pluteus-stage embryos or tissue fractions in $2 \%$ SDS, $10 \mathrm{M}$ urea, $10 \mathrm{~mm}$ Tris/Cl, (pH 7.0), 2 mM EDTA, $1 \mathrm{~mm}$ DTT were separated by polyacrylamide gel electrophoresis on $7.5 \%$ gels. All samples were applied to the gel at similar $(1-4 \mu \mathrm{g} / \mu \mathrm{l})$ protein concentrations with identical amounts loaded for each sample lane. Sample concentrations were determined using both Lowry and Bradford protein assays; the two methods were in close agreement. The gel was then electroblotted to a nitrocellulose membrane. The membrane was incubated in a $1: 250$ dilution of antiserum or preimmune serum and then with radioiodinated protein A. Autoradiography was carried out after washing the Western blot.

Immunofluorescent micrographs were obtained using wholemount pluteus-stage embryos reacted with the described antibodies and then with fluorescein-labeled goat anti-rabbit IgG. Pluteus larvae were stained at an antiserum dilution of $1: 50$. We consider this quite concentrated compared with antisera raised to complete proteins, but feel that both the highly ordered collagen structure as well as the short sequence represented in the synthetic peptide contribute to the observed low immunoreactivity. A Leitz microscope equipped for epifluorescence was employed for all studies.

For construction of the collagen probe plasmid, pSUDCol171 (Venkatesan et al. 1986) was restricted with EcoRV and AccI. The 237-bp fragment consisting mostly of exon sequences was isolated by preparative gel electrophoresis, blunt-ended with the Klenow fragment of DNA polymerase and dNTPs, and subcloned into pGEM2 (Promega Biotec) cleaved with SmaI and treated with calf intestinal alkaline phosphatase. The recombinant was restricted with either HindIII or EcoRI. ${ }^{35} \mathrm{~S}$-Labeled antisense and sense transcripts were synthesized with Sp6 and T7 RNA polymerase, respectively, as described previously (Cox et al. 1984). Specific activities were $4-5 \times 10^{8} \mathrm{dpm} / \mu \mathrm{g}$. Sections were hybridized with probe and slides were washed as described previously (Angerer and Angerer 1981) with the following modifications: the hybridization buffer included 100 mM DTT (dithiothreitol), coverslips were removed in $4 \times$ SSC containing $10 \mathrm{~mm}$ DTT, sections were dehydrated by passage through a graded ethanol series containing $300 \mathrm{~mm}$ ammonium acetate and incubated in hybridization buffer containing $10 \mathrm{mM}$ DTT at $65^{\circ} \mathrm{C}$ for $10 \mathrm{~min}$ before proceeding to the RNase digestion step. In some hybridizations shown here, efforts were made to reduce backgrounds by prehybridization incubation of sections with $10 \mathrm{mM} \mathrm{N}$-ethylmaleimide and $10 \mathrm{~mm}$ iodoacetamide in the presence of DTT, but this treatment did not significantly affect either signal or noise levels. After coating with NTB-2 emulsion, slides were exposed for either 1 (16-cell and 19-hr embryos) or 2 (23-, 42-, and 68-hr embryos) weeks, developed, and stained as described previously (Cox et al. 1984). Solution hybridizations were carried out and analyzed as previously described (Lynn et al. 1983).

\section{Acknowledgments}

We thank Dr. Frank Robey (Center for Drugs and Biologics) for his generosity in synthesizing the peptide used for the immunological studies; and Mrs. Bonnie Richards for preparation of the manuscript. This work was supported by a grant from the $\mathrm{Na}$ tional Institutes of Health (GM 25553).

\section{References}

Angerer, L.M. and R.C. Angerer. 1981. Detection of poly $\mathrm{A}^{+}$RNA in sea urchin eggs and embryos by quantitative in situ hybridization. Nucleic Acids Res. 9: 2819-2840.
Angerer, R.C. and E.H. Davidson. 1984. Molecular indices of cell lineage specification in sea urchin embryos. Science 226: $1153-1160$.

Benson, S., H. Sucov, L. Stephens, E. Davidson, and F. Wilt. 1987. A lineage-specific gene encoding a major matrix protein of the sea urchin embryo spicule. I. Authentication of the cloned gene and its developmental expression. Dev. Biol. 120: 499-506.

Blankenship, J. and S. Benson. 1984. Collagen metabolism and spicule formation in sea urchin micromeres. Exp. Cell Res. 152: 98-104.

Cox, K.H., D.V. DeLeon, L.M. Angerer, and R.C. Angerer. 1984. Detection of mRNAs in sea urchin embryos by in situ hybridization using asymmetric RNA probes. Dev. Biol. 101: 485-502.

Cox, K.H., L.M. Angerer, J.J. Lee, E.H. Davidson, and R.C. Angerer. 1986. Cell lineage-specific programs of expression of multiple actin genes during sea urchin embryogenesis. $I$. Mol. Biol. 188: 159-172.

Crise-Benson, N. and S.C. Benson. 1979. Ultrastructure of collagen in sea urchin embryos. Wilhelm Roux's Arch. 198: $65-70$.

Fink, R.D. and D.R. McClay. 1985. Three cell recognition changes accompany the ingression of sea urchin primary mesenchyme cells. Dev. Biol. 107: 66-74.

Harkey, M.A. and A.H. Whiteley. 1980. Isolation, culture, and differentiation of echinoid primary mesenchyme cells. Wilhelm Roux's Arch. 189: 111-121.

- 1983. The program of protein synthesis during the development of the micromere-primary mesenchyme cell line in the sea urchin embryo. Dev. Biol. 100: 12-28.

Hynes, R.O. and P.R. Gross. 1970. A method for separating cells from early sea urchin embryos. Dev. Biol. 21: 383-402.

Ishimoda-Takagi, T., I. Chino, and H. Sato. 1984. Evidence for the involvement of muscle tropomyosin in the contractile elements of the coelom-esophagus complex in sea urchin embryos. Dev. Biol. 105: 365-376.

Lynn, D.A., L.M. Angerer, A.M. Bruskin, W.H. Klein, and R.C. Angerer. 1983. Localization of a family of mRNAs in a single cell type and its precursors in sea urchin embryos. Proc. Natl. Acad. Sci. 80: 2656-2660.

Martin, G., R. Timpl, P.K. Muller, and K. Kuhn. 1985. The genetically distinct collagens. Trends Biochem. Sci. 10: 285287.

McClay, D.R. 1986. Embryo dissociation, cell isolation, and cell reassociation. In Methods in cell biology led. T.E. Schroeder), vol. 27, pp. 309-323. Academic Press, New York.

Mintz, G.R., S. DeFrancesco, and W.J. Lennarz. 1981. Spicule formation by cultured embryonic cells from the sea urchin. J. Biol. Chem. 256: 13105-13111.

Pehrson, J.R. and L.H. Cohen. 1986. The fate of the small micromeres in sea urchin development. Dev. Biol. 113: 522526.

Pittman, D. and S.G. Ernst. 1984. Developmental time, cell lineage, and environment regulate the newly synthesized proteins in sea urchin embryos. Dev. Biol. 106: 236-242.

Pucci-Minafra, I., C. Casano, and C. LaRosa. 1972. Collagen synthesis and spicule formation in sea urchin embryos. Cell Diff. 1: 157-165.

Okazaki, K. 1975. Spicule formation by isolated micromeres of the sea urchin embryo. Amer. Zool. 15: 567-581.

Sucov, H.M., S. Benson, J.J. Robinson, R.J. Britten, F. Wilt, and E. Davidson. 1987. A lineage-specific gene encoding a major matrix protein of the sea urchin embryo spicule. II. Struc- 


\section{Angerer et al.}

ture of the gene and derived sequence of the protein. Dev. Biol. 120: 507-519.

Venkatesan, M., F. De Pablo, G. Vogeli, and R.T. Simpson. 1986. Structure and developmentally regulated expression of a Strongylocentrotus purpuratus collagen gene. Proc. Natl. Acad. Sci. 83: 3351-3355.

Wessel, G.M. and D.R. McClay. 1985. Sequential expression of germ-layer specific molecules in the sea urchin embryo. Dev. Biol. 111: 451-463.

. 1987. Gastrulation in the sea urchin embryo requires the deposition of crosslinked collagen within the extracellular matrix. Dev. Biol. 121: 149-165.

Wessel, G.M., R.B. Marchase, and D.R. McClay. 1984. Ontogeny of the basal lamina in the sea urchin embryo. Dev. Biol. 103: 235-245.

Wu, T.-C. and R.T. Simpson. 1985. Transient alterations of the chromatin structure of sea urchin early histone genes during embryogenesis. Nucleic Acids Res. 13: 6185-6203. 


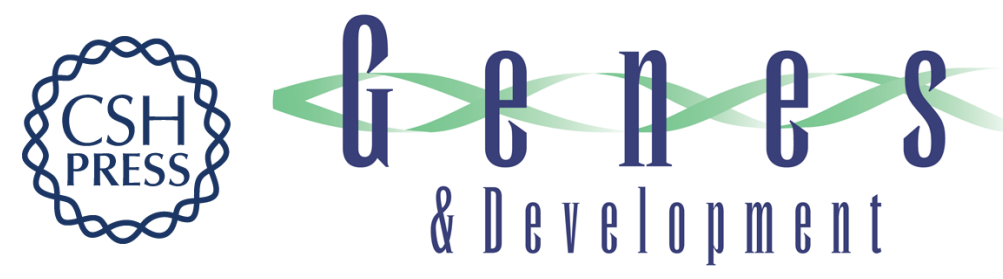

\section{Expression of a collagen gene in mesenchyme lineages of the Strongylocentrotus purpuratus embryo.}

L M Angerer, S A Chambers, Q Yang, et al.

Genes Dev. 1988, 2:

Access the most recent version at doi:10.1101/gad.2.2.239

References This article cites 25 articles, 4 of which can be accessed free at: http://genesdev.cshlp.org/content/2/2/239.full.html\#ref-list-1

License

Email Alerting

Receive free email alerts when new articles cite this article - sign up in the box at the top Service right corner of the article or click here.

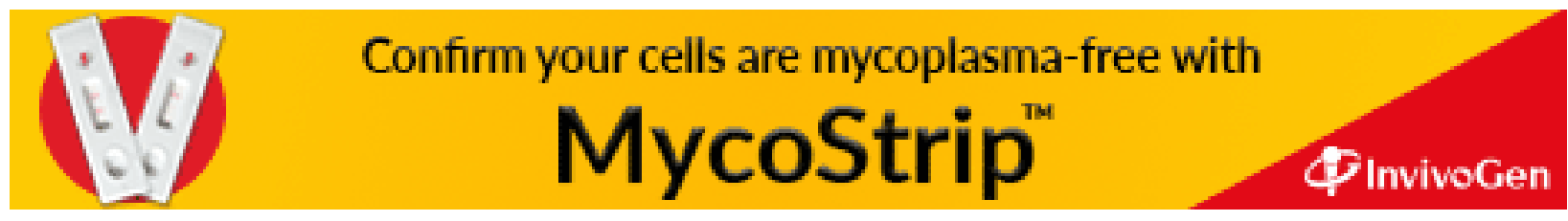

